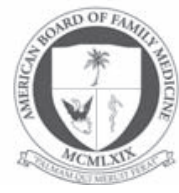

From the American

Board of Family Medicine

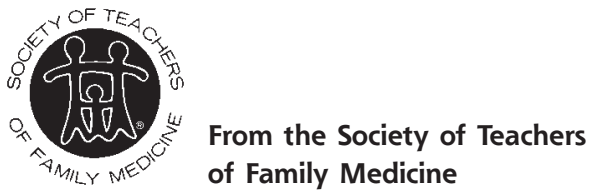

Ann Fam Med 2007;5:564-565. DOI: 10.1370/afm.785

\section{UPDATE ON THE IN-TRAINING EXAMINATION}

For more than 25 years, the In-training-Examination (ITE) of the American Board of Family Medicine (ABFM) has been a valuable resource for residency programs. An unusual aspect of this examination is that since 1981 an international program at the American University of Beirut has administered the ITE to its residents on the same day that it was given to residents in the United States. While Beirut's residents were not included in the scoring statistics, they received the same score reports as their American counterparts, allowing them to compare their performance to US residency programs.

In 2006, the ABFM introduced an Internet-based version of the ITE in a pilot project. This allowed the ABFM to expand the use of the ITE to other international programs. In Australia, physicians from the Australian College of Rural and Remote Medicine (ACRRM) were able to take the ITE. In addition, Dr Chris Place, Program Director of the Hope Family Medicine Residency Program in Macao, The People's Republic of China, worked with the ABFM to have his residents take the examination. The success of the pilot project both in the United States and also with the 2 international programs has resulted in the ABFM expanding the Internet-based delivery of the ITE, utilizing a large commercial testing organization for administration. In 2007, it is expected that additional international programs will take advantage of the Internet-based version. Dr Timothy Fader of the Family Medicine Residency Program of Kabul, Afghanistan and Dr Roy Ringenberg of the Family Medicine Residency Program of Quito, Ecuador are working with the ABFM to have their residents take the ITE in 2007.

Given the interest of international groups in the ITE, the ABFM is working with a number of organizations and individuals to improve the process by developing translated versions of the examination. While currently these efforts are focused on individual volunteers, the ABFM hopes to obtain funding to support these activities in the future.

Richard Rovinelli, $\mathrm{PbD}$ Technology Advisor

\section{STFM ANNUAL CONFERENCE THEME: STRENGTHEN CORE \& STIMULATE PROGRESS: ASSEMBLING PATIENT- CENTERED MEDICAL HOMES}

Two plenary presentations at the 2007 Annual Spring Conference in Chicago reinforced the choice of this theme, as have recent announcements about the Patient-Centered Medical Home and the Patient-Centered Primary Care Collaborative by the American Academy of Family Physicians (AAFP).1,2

In his plenary address at the 2007 Annual Spring Conference, Terry McGeeney repeatedly said "Houston, we have a problem." He described the disheartening state of family medicine clinical practice revealed by the TransforMED project. Jim Mold, in his plenary presentation, presented an optimistic picture of a statewide learning community that can lead to practice improvement, but his data showed far from optimal performance. While family medicine may still have a problem, there is a solution. By assembling patient-centered medical homes, family medicine can strengthen the provision of its core clinical services and stimulate progress toward optimal high quality care.

The AAFP is promoting the patient-centered medical home $(\mathrm{PCMH})$ through the TransforMED project, the Patient-Centered Primary Care Collaborative (PCPCC), and advocacy in Congress. The American Board of Family Medicine (ABFM) and the Association of Family Medicine Residency Directors (AFMRD) are fostering the $\mathrm{PCMH}$ vision in residencies in the Preparing the Personal Physician for Practice ( $\left.\mathrm{P}^{4}\right)$ Project. STFM seeks to spread the PCMH model to all teaching practices-medical school faculty, residency program, and community preceptor practices-by promoting a teaching practice learning community to help remodel the hundreds of teaching practices in family medicine educational programs.

STFM joined the $\mathrm{PCPCC}^{3}$ to advocate for this model of care. The Institute for Family-Centered Care ${ }^{4}$ and the New Health Partnerships 5 also advocate for patient- and family-centered care. Attention to linkages around patient care is consistent with STFM's mission statement and its responsibilities for the Future of Family Medicine strategic priorities. 